\title{
Evaluation of China's National Designated Poor County Policy
}

\author{
Jialu $\mathrm{Gu}^{1}$, a \\ ${ }^{1}$ School of xxx, Nanjing University of Chinese Medicine, Nanjing 210000, China \\ a120043873@qq.com
}

Key words: NDP County, poverty relief, policy evaluation

\begin{abstract}
Chinese central government car ried out the National Designated Poverty (NDP) County Policy in the 1880 s, aiming to reduce the amount of the poor, improve the life quality and balance the development of different districts. To probe into the effect of the policy, this paper sorts out the 4 phases of the policy and collects related researches. It found that although the incidence of poverty and the amount of the poor had decreased a lot in the past decades, there were still many problems existing in NDP counties. Dealing with the problems successfully will be crucial to the completion of 2020 plan, whose goal is to lift all the residents above the poverty line.
\end{abstract}

\section{Introduction}

The (NDP) County policy can be divided into 4 phases until now. In 1986, the central government decided the NDP counties for the first time. Then, from 1994 to 2000 "The 8-7 Poverty Alleviation Project" was carried out. 2001 to 2010 was the third phase of the policy and now we are in the last phase from 2011 to 2020 . Some great achievements have already been achieved until now. In 1986, the number of people in absolute poverty was about 125 million, however, according to the standard in 2010, the number had decreased to 26 million 880 thousand. Although the achievement was remarkable, there was no denying that some drawbacks had emerged, for example, some cheered for the admission of Designated Counties, some scattered the anti-poverty funds, the other refused to be removed from the list of Designated Counties. These have aroused wide public concern and people began to doubt the policy as well as considered about the real effect of it.

This paper is organized as follows. Section 2 provides the background of the NDP county policy in different phases. Section 3 introduces the Case Analysis and the Empirical Evidence respectively. Eventually, section 4 offers concluding remarks.

\section{Background}

In 1986, Chinese central government launched the NDP County Policy for the first time, aiming to support and encourage the poor to improve the production, exploit the local resources, develop the commodity economy and strengthen the ability of self-accumulation and self-development. Unlike earlier emphasis on poverty relief in poor households' consumption, the central government harbored the hope that poor farmers could get rid of poverty and provided adequate food and clothing with their own efforts. At that time, the main criterion for NDP County selection was that rural net income per capita went below 150 Yuan in 1985 while the criterion for old revolutionary areas and ethnic minority areas was 200 Yuan. Besides, the old revolutionary bases which had made great contributions to Chinese revolution and some poverty-stricken minority autonomous counties of Neimeng, Xinjiang and Qinghai provinces extended the criterion to 300 Yuan.

The first adjustment of poor counties was after the 1994 tax distribution reform, at which time the 
county's task force for poverty alleviation had made great progress. Although the total impoverished population had decreased to 80 million, most of them lived in considerably remote areas with poor transportation systems and backward economy, culture and education, bringing a big challenge to the poverty alleviation. According to the situation, the central government decided to carry out The 8-7 Poverty Alleviation Project, which was a plan to lift 80 million rural poor out of poverty from 1994 to 2000 with great manpower, material and financial resources. Rural net income was still as the criterion for selection Designated counties, the only difference was that range had turned into 400 Yuan to 700 Yuan.

In 2001, the government adjusted the criterion again, all the counties in coastal areas were excluded from the list, at the same time, the number of western counties was raised to 592 and remained unchanged. Different from the former, The State Council's Leading Group Office of Poverty Alleviation and Development (SCLGO) gave provinces authority to decide the list of counties. The central government just allocated the amount of counties of different provinces according to ' 631 index method'. What's more, the focus of poverty alleviation had turned to poverty-stricken villages. Under the guidance of SCLGO, the local poverty alleviation department decided the list of 148 thousand poor villages nationwide through Participant Pattern and other methods as well as the Whole Village Advance Pattern to support the development. This change gave the poor the chance to enjoy the poverty alleviation policies and funds even if they were not included in the poverty-stricken counties.

The third adjustment happened in 2012, when SCLGO entitled the provinces to decide the list of poor counties completely as long as the provinces were in conform with the rule 'high out low in, one out one in, strict procedure, unchanged amount'. The official poverty line had been raised to 2300 Yuan on the basis of rural net income per capita and become more scientific, which considered the basic necessities of living and the necessities of development, the average level of nation and the standard of different provinces as well as the national reality and the international standard. Besides, the central government designated the contiguous poor areas, which were the main battlefield in the new period. The whole 14 contiguous poor areas simply covered most of the poor and povertystricken areas. Since the routine methods were exhausted, further efforts and strengthened methods were put into these areas to help carry out the poverty-relief program. The additional central government special funds for poverty alleviation were mainly used to construct the contiguous poor areas too.

To help the Designated Counties remove poverty quickly, the central government had set out a series of preferential policies. In terms of financial anti-poverty funds, all the work relief funds and most of the development funds were used to reduce poverty. The Designated counties were the center of agricultural programs supported by the credit poverty alleviation fund. The agricultural taxes could be exempted prior to other counties. Training of rural transferring labor force was implemented mainly in Designated Counties. The 'One Fee for All' policy in compulsory education and 'Two Exemptions and One Subsidy' policy were all started from the Designated Counties. Additionally, the government is pushing on the full coverage of financial institutions and services to perfect Poverty Alleviation Interest Loan Policy and promote the micro-credit loans, which can meet the need of finance to develop the production. Pushing forward infrastructure construction is also taken into consideration, which will not only increase employment but also help build up relevant facilities for economic development.

\section{Evaluation}

Case Analysis. The development of the NDP counties has won great attention from the society for a 
long time and the media have reported many problems existing in these counties. Firstly, many local officials lack thorough understanding of the situation in counties and the role government should play in the process of poverty alleviation. Xinshao County in Hunan Province was a typical example, who cheered for the admission of Designated Counties instead of learning from the painful experience to strive for development.

Then, the implementation of poverty alleviation policy hasn't been supervised effectively until now, so, the policy can't really benefit the public. It can be explained in three aspects. First, although the counties have gained fast development, the living standard of rural residents haven't been improved. To illustrate, Zhunger Banner, Inner Mongolia was rich in coal resource, for which, the central government encouraged coal mining to help the local economy. However, the developers were mainly State-owned Key Enterprises and enterprises belonging to Inner Mongolia Autonomous region. What's more, they tended to use modern large machinery rather than employ the local people. As a result, Zhunger Banner had made great progress with its masses still poor. Second, the local government scatters the anti-poverty funds instead of making the most of them. Hengshan County, Shanxi Province spent about 100 million yuan constructing the 23 floors' government office building; Ningling County, Henan Province spent over 10 million yuan creating the office building; Gushi County, Henan Province invested approximately 200 million yuan in building the administrative service center, whose area over 30 thousand square meters. Such examples are endless but in fact, many counties even can't reach "eat meal" level in terms of finance. Third, the central government pays so much attention to the poverty alleviation in counties and villages that almost all the work force and funds flow into these areas while the poor people in impoverished counties and villages haven't won the support. Until now, 41 percent of the poor people distribute in impoverished villages and 45 percent in impoverished counties. Therefore, to take targeted measures in poverty alleviation is rather significant.

Finally, many counties are not willing to be removed from the list of NDP counties even though they have gotten out of poverty. Some NDP counties are even included in China's top one hundred strongest counties. For instance, Zhunger Banner, Inner Mongolia, who ranks 12 in China's one hundred top counties and 1 in Western China's one hundred top counties, is still in the list of NDP counties. Not come singly but in pairs, Yijinhuoluo Banner, Inner Mongolia and Fugu County, Shanxi Province have the same case. The existence of "Fake NDP counties" demonstrates the defect of entry and exit mechanism as well as the methods, such as "the back door"、 "public relations" and so on the local government use to enjoy the preferential measures and poverty alleviation funds. As a result, the counties in need of help are excluded the NDP counties, which deepen the unfair distribution of interests.

Through the above cases, it can be concluded that the various problems in NDP counties are related to the criterion for choosing NDP counties. For one, the selection is not open and transparent and the procedure is not strict, for another, the criterion usually last for a long period, when the economy and society has changed a lot. Both the drawbacks give the local government the chance to "thumb a ride".

Empirical Evidence.The NDP counties have received great support from central government for a long time. According to the estimate of Li and Wang (2004) [1], the poverty rate increased by one percent in NDP counties, per capita poverty alleviation fund, three central poverty alleviation fund, special loan for poverty alleviation, financial development fund and work relief fund will increase respectively for 0.76 yuan, 0.90 yuan, 0.46 yuan, 0.20 yuan and 0.23 yuan. It indicates that the distribution of most of the poverty alleviation funds indeed inflow into poverty-stricken counties. Besides, more and more funds are put into the poor western districts, mountain areas, old 
revolutionary base areas, minority regions and border areas.

However, the usage of the financial funds is unreasonable. Liu and Ma (2015) [2], Mao et al. (2012) [3], Li et al. (2003) [4] found that the frequent transfer of poverty alleviation funds increased the finance expenditure of local government yet the structure of the expenditure was not improved and the accuracy of poverty alleviation was not enough through empirical research. Admittedly, there is a conflict among their conclusion. Mao et al. (2012) [3] contended that poverty alleviation would not distort public expenditure decision made by local government, during The 8-7 Poverty Alleviation Project, the expense of administration in total finance expenditure in NDP counties reduced by 2-2.6 percent in comparison with that in other districts while the productive public expenditure and educational expenses increased by 10 percent. On the contrary, Li et al. (2003) [4] argued that when it faced with risk of financial deficit, the expense of administration is the most stable in rural public goods because it had the strongest rigidity and account for a large proportion in total finance expenditure. Inversely, the educational expenses are the most unstable. Liu and Ma (2015) [2] supported the opinion of Li et al. (2003) [4] and pointed out transfer of poverty alleviation funds would increase the proportion of expense of administration and reduce the educational expenses.

At last, many experts have studied the effect of poverty alleviation policy. Wang and Liu (2016) [5] found that although the fluctuation degree of the effect was different in the counties, the performance of the policy was remarkable in general. Poverty alleviation policy had long term effect on 61 percent of the 158 NDP counties in the research. The effect could be attributed to two aspects. From the short term, the poor areas with low rural per capita net income gained more support from central government, because of which, it received more funds and resources to improve the life quality. From the long term, the increase of per capita finance expenditure was the main reason. Finance expenditure could add to the income of poor people, improve their life condition by transfer payment and social security expenditure. Wang and Li (2003) [6] also found that with the increase of per capita net income, poverty had been eased and the incidence and degree of poverty had decreased. However, the policy effect maybe negative to some counties. As to these counties, poverty alleviation funds can just relieve the poverty to some degree instead of solving the problem thoroughly. Accordingly, Wang and Liu (2016) [5] considered that the ability to cope with poverty risk should also be paid attention to as well as the poverty alleviation policy. Wang and $\mathrm{Li}$ (2003) [6] added that income from working outside and private business were the key point to the increase of income. Therefore, to ensure the increase of income in rural areas, investment environment should be improved in poor areas to create more chances for non-agricultural activities and private business.

\section{Conclusion}

According to the above analysis, NDP county policy indeed improved the situation in NDP counties, however, with the further development of the policy, problems began to be exposed, which threatened the effect of the policy. To achieve the goal that all the people get out of the poverty in 2020 , there are some points to be improved. First, the central government should perfect the entry and exit mechanism of poor counties and make reasonable and scientific evaluation standards. At the same time, prefect the supervision system is also important because the supervision of the government, the masses and the media will make the selection of NDP counties more transparent. Second, increase the accuracy of poverty alleviation. It is not only necessary to increase the Fiscal transfer expenditure to the poor counties, but also the poor people in non-poverty counties, which will help avoid the dead corner in the process of poverty alleviation. Third, in addition to increase the Fiscal transfer expenditure to improve the life standard, the central government should also improve the poor's ability to resist poverty. More chances need to be created to boost employment to form steady income. 
Fourth, change the 1:1 counterpart funds system and adjust the system according to the local condition to decrease the local government's burden of debt. At last, the local government should optimize the structure of financial expenditure. To make the most of the public resource and build up the efficient government, reducing the personnel and the expense of administration are relatively are necessary.

\section{References}

[1] Li Wen, \& Wang San gui. (2004). The allocation of central poverty alleviation funds and the analysis of influence factor. West, 92(61.20), 16-64.

[2] Liu Chang, \& Ma Guang rong. (2015). Will fiscal transfer lead to" flypaper effect"?--The new evidence from regression discontinuity. Journal of Economics, (1), 25-46.

[3] Mao Jie, Wang De hua, \& Bai Zhong en. (2012). Poverty alleviation and public expenditure of local government--An empirical study based on "The 8-7 Poverty Alleviation Project". The Quarterly Journal of Economics, 11(3), 1365-1388.

[4] Li Bing long, Zhang Li cheng, \& Cao Jian. (2003). Study on the impact of local fiscal deficit on rural pubic goods in China's poverty areas. China Rural Survey, (1), 23-30.

[5] Wang Yi ming, \& Liu Zhi hong. (2016). The evaluation of the policy effect of large public expenditure projects --Taking "87 poverty alleviation program" as an example. Economics of Finance and Trade, 37(1), 33-47.

[6] Wang San gui, \& Li Wen. (2003). The change of farmers' income in poor counties and its cause analysis. Issues in Agricultural Economy, (3), 19-24. 